ICRES 2019: International Conference on Robot

Ethics and Standards, London, UK, 29-30 July 2019.

https://doi.org/10.13180/icres.2019.29-30.07.018

\title{
WHEN CHILDREN NAVIGATE RPAS: STEPS TOWARDS SAFE RECREATION DRONE FLYING
}

\author{
MARIA ISABEL ALDINHAS FERREIRA
}

Centro de Filosofia da Universidade de Lisboa. Faculdade de Letras da Universidade de Lisboa

University of Lisbon, Portugal

and

Instituto Superior Técnico/ Institute for Systems and Robotics

University of Lisbon. Lisbon, Portugal

\section{isabelferreira@letras.ulisboa.pt}

\begin{abstract}
The use of drones has been growing with the production nowadays targeting four main markets that could be identified as: military, governmental, commercial, and hobby.

The present paper identifies the main steps already taken by the EU towards the definition of a framework that guarantees their correct deployment in all member states and identifies a series of further steps to be taken in what concerns the open category of leisure/recreation drones in a society where school children already manipulate them and where some 7 million consumer leisure drones are expected to be operating across Europe in $2050^{1}$.
\end{abstract}

Keywords: Leisure/Recreation Drones, EU Drone Roadmap, Educating Citizens, Learning Drone Flying Rules at School

\section{Introduction}

The introduction of new technologies always impacts the way human beings act and structure their reality giving rise to new patterns of behavior, new ways of living, to different habitats. These changes that emerge from the incorporation of new forms of technological innovation in human physical, social and cultural

\footnotetext{
${ }^{1}$ European Drones Outlook Study- Unlocking the value for Europe. SESAR European Drones Outlook Study. November 2016
} 
environment generally ask for the consequent emission of social and legal regulations so that individual and collective rights and well-being are safeguarded in a new existential framework. Drones are probably the embodied forms of robotic technology that the general public knows best, as these robots are already effectively populating human environment. 'Drone' usually designates an unmanned aircraft system (UAS) or unmanned aerial vehicle (UAV) which includes, as a subset, remotely piloted aircraft systems (RPAS). UAS/UAV generally refer to military applications while RPAS usually refer to the civilian ones ${ }^{2}$. In general terms, drones could be just defined as aerial robots, at present, remotely controlled by human beings. This broad category comprehends artifacts of differentiated sizes, weight, engine power, range....their production targeting four main markets that could be identified as: governmental/military and civilian comprehending both commercial and hobby/recreational markets.

During the last decade, drones were mostly known for their use in defense or warefare, frequently reported in the news ${ }^{3}$. However, drones have been assuming a closer and more "amicable" role in the common daily life being responsible for the surveillance of fire risk in forests, delivering goods, media use: e.g., photographing big public events as music concerts or football matches; mapping.... and they have also integrated the private sphere photographing weddings or any other kind of personal celebrations or even simply serving as an entertainment/recreation tool for all members of the family.

A recreational drone is defined in Schedule 1 of the ANO ${ }^{4}$ as "any unmanned aircraft, other than a balloon or a kite, having a mass of not more than $20 \mathrm{~kg}$ without its fuel but including any articles or equipment installed in or attached to the aircraft at the commencement of its flight". To this definition we would add a very important element- its function: having the purpose of entertaining its end-user.

However, it is in this personal amicable sphere of use that drones have revealed themselves as highly disruptive. The number of sightings and incidents with recreation drones has been raising exponentially in developed countries at airport vicinities and conventionalized aerial space (Fig 1) assuming this phenomenon one of its peaks in 2018 when Gatwick Airport closed after several reports of drone sightings. This disrupted about 140.000 passengers whose

\footnotetext{
${ }^{2}$ M. de Miguel Molina and V. Santamarina Campos (eds.), (2018) Ethics and Civil Drones, SpringerBriefs in Law, https://doi.org/10.1007/978-3-319-71087-7_2 ${ }^{3}$ https://edition.cnn.com/2019/06/20/middleeast/iran-drone-claim-hnk-intl/index.html

${ }^{4} 1$ CAA, CAP1687: Air Navigation (Amendment) Order 2018 - Guidance for small unmanned aircraft users, July 2018
} 
flights were either cancelled or significantly delayed during the nearly 36 hours in which the airport was closed with the consequent huge financial consequences.

\section{Drohnen in der Nähe von Flughäfen}

\section{Gemeldete Behinderungen durch Drohnen}
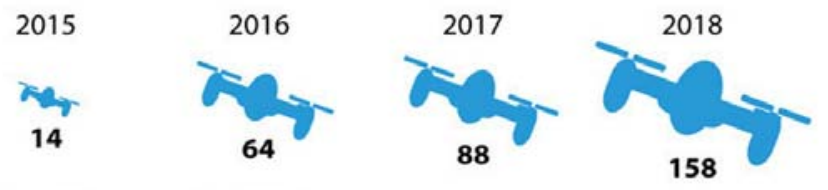

Flughäfen mit den häufigsten

Behinderungen 2018
Frankfurt a. M.
Berlin-Tegel
München
Hamburg
Berlin-Schönefeld
Köln/Bonn
Stuttgart

Drohnen-Sichtungen

Figure 1: Drone Sighting at the vinicity of German Airports ${ }^{5}$

It is precisely the rising number of incidents caused by these recreation applications and its imminent danger to aerial navigation that has urged the EU to define a regulatory framework to which, in the short term, all stakeholders will have to comply. However in the present state of affairs when thousands of recreation drones have already been easily acquired by consumers of all ages, either online $e^{6}$ or in the traditional retail, and some 7 million consumer leisure drones are expected to be operating across Europe in 2050, the emission of

\footnotetext{
https://www.thelocal.de/20190122/drones-cause-record-number-of-air-traffic-disruptions-ingermany

${ }^{6} \mathrm{Cfhttps}: / /$ www.gearbest.com/promotion-RC\%20Clearance\%20Sale209.html?vip=4270344\&gclid=CjwKCAjwh9_bBRA_EiwApObaOByF9s0Zyeq7usc8OpnzFDqZ HKduzpZ6CxpN3zt-fJk-PcthiO_YDBoCGAMQAvD_BwE
} 
legal/regulatory norms should be accompanied by other specific initiatives targeting potential consumers.

\section{RPAS Regulatory Framework A Roadmap}

As pointed out above, the introduction of a new form of technology in society always demands the definition of regulatory and legislative frameworks capable of guaranteeing its safe and correct deployment. If the domains of military and governmental drones use have to comply with general strict military or governmental rules, already established for those fields, the same is not true in what concerns other applications, especially those destined to recreational purposes.

Considering the emergence of RPAS, their potential benefits for European citizens and economy as well as the lack of an internal market in this area, DG Enterprise and Industry ${ }^{7}$ and DG Mobility and Transport ${ }^{8}$, in close consultation with other Commission services, launched, on the 23 June 2011 at the Paris International Air Show, a broad stakeholders' consultation, later called the "UAS Panel Process", with the aim to contribute to the definition of a Strategy for the development of civil applications of RPAS in Europe. The "UAS Panel Process" was open to the most relevant stakeholders and analyzed the barriers to a full exploitation of civil (commercial, corporate and governmental nonmilitary) RPAS in Europe, discussing possible ways forward to overcome them. The "UAS Panel Process" consisted of two fundamental elements: (a) a call to all interested stakeholders to provide information and comments on the need for a Strategy for RPAS in Europe and (b) the organisation of 5 thematic workshops from July 2011 to February 2012.

As a result of this process, the European Commission published in September 2012 a working document on the civil use of drones - Towards a European strategy for the development of civil applications of Remotely Piloted Aircraft Systems (RPAS) ${ }^{9}$. This working paper recognized that the potential of this

\footnotetext{
${ }^{7}$ Directorate General of the European Commission responsible for Enterprise and Industry

${ }^{8}$ Directorate General of the European Commission responsible for Mobility and Transport.

${ }^{9} \mathrm{https} / / /$ circabc.europa.eu/sd/a/3a6d53da-0197-4fa7-

8c9001637cb57055/Commission\%20Staff\%20Working\%20Document\%20(SWD(2012)259)\%20-

$\% 20$ Towards $\% 20 \mathrm{a} \% 2$
} 
technology to create new businesses and support industrial competitiveness is huge but that the emergence of the civil RPAS market was hampered by the absence of an operational concept and associated technical enablers as well as a supporting regulatory framework; clear rules, mainly on the pilots and on the operations, being urgently needed (ibidem,2012:5-10). As a consequence the European Commission assigned the planning and coordination of work on civil drones to a steering committee. This steering group presented, in 2013, its recommendations to all type of drones, except model aircraft and toys. ${ }^{10}$ and in April 2014 plans were made to create a single European market for drones by harmonising airworthiness and operations regulations..

On its hand, the European aviation community, in Riga on 5-6 March 2015, defined the following principles to guide the drone regulatory framework in Europe:

1. Drones should be treated as new types of aircraft and regulated proportionally to the risk of each operation.

2. Safety rules for drones should be developed urgently at the EU level.

3. Public authorities and the industry should invest in the technologies and standards in order to integrate drones into the EU aviation system.

4. Public acceptance of drone services is of key importance. Privacy and the protection of personal data should be guaranteed.

5. The drone operator should be responsible for its use. It should be possible to identify him or her, as via ID chip.

However the increasing rising number of incidents caused by leisure drones near airports' aerial space urged EU to speed up the emission of a broad legislative framework to be applied by all member states. The European Aviation Safety Agency (EASA) was tasked by the Commission to develop a set of European rules for drones and the EASA's final proposals were presented in September 2015. The formal regulatory reform process began in December 2015 when the Commission proposed to create an EU-wide framework for drones as part of its Aviation Strategy The Commission specifically proposed to abolish the initial 150 kilograms threshold and EASA subsequently published 'prototype' regulation for to the operation of unmanned aircraft in the 'open'

\footnotetext{
${ }^{10}$ RPAS Steering Group, Roadmap for the integration of civil Remotely-Piloted Aircraft Systems into the European Aviation System, June 2013

http://ec.europa.eu/enterprise/sectors/aerospace/uas/index_en.htm
} 
and 'specific' categories in August 2016. ${ }^{11}$."Open" category' designating a category of UAS operation that, considering the low risk involved, requires neither a prior authorisation by the competent authority nor a declaration by the UAS operator before the operation takes place; “"specific" category' meaning a category of UAS operation that, considering the risks involved, requires an authorisation by the competent authority before the operation takes place, taking into account the mitigation measures identified in an operational risk assessment, except for certain standard scenarios for which a declaration by the UAS operator is sufficient; https://www.easa.europa.eu/documentlibrary/opinions/opinion-012018

On the 22 December 2017, the Permanent Representatives Committee approved the first EU-wide rules for civil drones ${ }^{12}$ allowing remotely piloted aircraft of all sizes to fly safely in European airspace, providing the basic principles to ensure safety, security, privacy and the protection of personal data and establishing that higher-risk drone operations will require certification, while drones presenting the lowest risk will simply need to conform with the normal EU market surveillance mechanisms.

On 22 February 2018, EASA published the first Opinion on Safe Operations for Small Drones in Europe ${ }^{13}$. This Opinion approached the issue in a new way by combining product legislation and aviation legislation determining design requirements for small drones (up to $25 \mathrm{~kg}$ ) to be implemented by using the "Conformité Européenne" (CE) marking for products brought on the market in Europe and the inclusion in each drone package of a consumer information with the "do's and don'ts" on how to fly a drone without endangering other people. The new rules were voted and approved on 12 June 2018 by the European Parliament.

On 11 June 2019 further common European rules on drones, Commission Delegated Regulation (EU) 2019/945\& Commission Implementing Regulation (EU) 2019/947, ${ }^{14}$ According to Patrick Ky, Executive Director of EASE:

"Europe will be the first region in the world to have a comprehensive set of rules ensuring safe, secure and sustainable operations of drones both, for

11 EASA, 'Prototype' Commission Regulation on Unmanned Aircraft Operations, 22 August 2016; For further detail, see the relevant explanatory note

12 https://www.consilium.europa.eu/en/press/press-releases/2017/12/22/updated-aviation-safetyrules-and-new-rules-on-drones-approved-by-the-council/

13 https://www.easa.europa.eu/newsroom-and-events/press-releases/easa-publishes-first-opinionsafe-drone-operations-europe

${ }^{14}$ https://eur-lex.europa.eu/eli/reg_impl/2019/947/oj 
commercial and leisure activities. Common rules will help foster investment, innovation and growth in this promising sector” 15

The new rules include technical as well as operational requirements for drones. On one hand defining the capabilities a drone must have to be flown safely, e.g., new drones will have to be individually identifiable, allowing the authorities to trace a particular drone if necessary. On the other hand, the rules cover each operation type, from those not requiring prior authorization, to those involving certified aircraft and operators, as well as minimum remote pilot training requirements. The new rules will replace existing national rules in EU Member States. As the EASA website states ${ }^{16}$, the approach taken is to apply the highest safety standards achieved in manned aviation to drones as well.. The new rules ensure that drone operators - whether recreational or professional - will have a clear understanding of what is allowed or not.

\section{Recreation Drones: The end-users' universe}

The user-centred perspective, that should be at the core of the design definition and making of either tangible and non-tangible products, assumes that all artifacts, namely the technological artifacts, are determined in their architecture and design not only simply by the function they are supposed to perform but also by the specificities of the particular context of use, namely by anatomy and physiology of the end -user, by their psychology, education and life experience, by their expectations towards technology i.e., by the "User's Referential Framework"- URF (Ferreira 2017) and should comply to a set of essential parameters defining a prototypical context for the type of end-user under appraisal.

The market for recreational drones has been growing exponentially as devices become increasingly sophisticated and cheaper. It was estimated, for example, that British consumers purchased 530,000 drones in 2014 and that about 1.5 million were anticipated to be sold during the Christmas period of 2017. ${ }^{17}$

\footnotetext{
${ }^{15}$ ibidem

${ }^{16} \mathrm{Cf}$ https://www.easa.europa.eu/easa-and-you/civil-drones-rpas\#0

17 The House of Commons Library, Briefing Paper

Number CBP 7734, 11 February 2019

www.parliament.uk/commons-library | intranet.parliament.uk/commons-library | papers@parliament.uk | @commonslibrary
} 
But who are the end-users of recreation drones? To this question, no one is so far capable of giving an accurate answer, as any form of registration either when purchasing the product or afterwards, still lacks.

In order to have a rough idea about the prevalence of recreation drones in the domestic sphere, namely in households, a short survey, consisting of 4 questions, was conducted at a public school in the metropolitan area of Lisbon ${ }^{18}$ to a gender heterogeneous universe of about 150 school children (aged 11-14).

.1 Do you know what a drone is? Yes/ No

2. (If 1 is yes) Have you already flown one? Yes/No

3. (If 2 is yes) Is that drone yours? Yes/No

4. (If 3 is no) Whom does it belong to? Parents / Other Relatives/ Friends

The results of the survey to each of the queries were the following

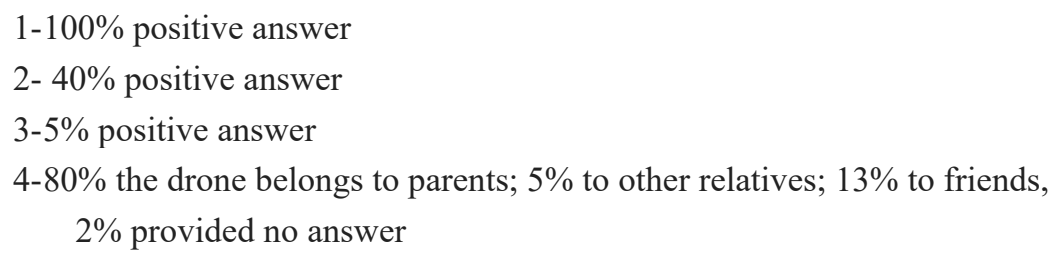

This brief survey allowed concluding that:

- The concept and the artifact are widely recognized among youngsters.

- A substantial percentage has already physically interacted with it.

-A significant percentage of children and teenagers have been operating either their own or someone else's drones.

This small sample illustrates the urge to accompany legislative efforts with raising awareness campaigns via media and the web targeting potential young consumers and identifying the do's /don'ts of drone use

For instance, in the UK, the Civil Aviation Authority (CAA) has been running a long standing 'Dronecode' guide (Fig 2) and 'Dronesafe' campaign (Fig 3) to help to raise awareness amongst the general public and potential drone pilots to

\footnotetext{
${ }^{18}$ Agrupamento de Escolas Emídio Navarro- Almada.Portugal
} 
the basics of safe drone flying and identical strategies have been defined by other European and non European states.

However, the very probable prevalence of very young inexperient pilots (in spite of the proposed legislative threshold of 16) in the recreation pilots group calls for the implementation of long-standing educational measures that should take place at school. These should assume the form of yearly subjects during the curriculum, possibly in the $7^{\text {th }}$ and $8^{\text {th }}$ grades. There the students would learn the basics of drone architecture and operating system as well as the essential rules and procedures to be observed in order to responsibly drone flying.

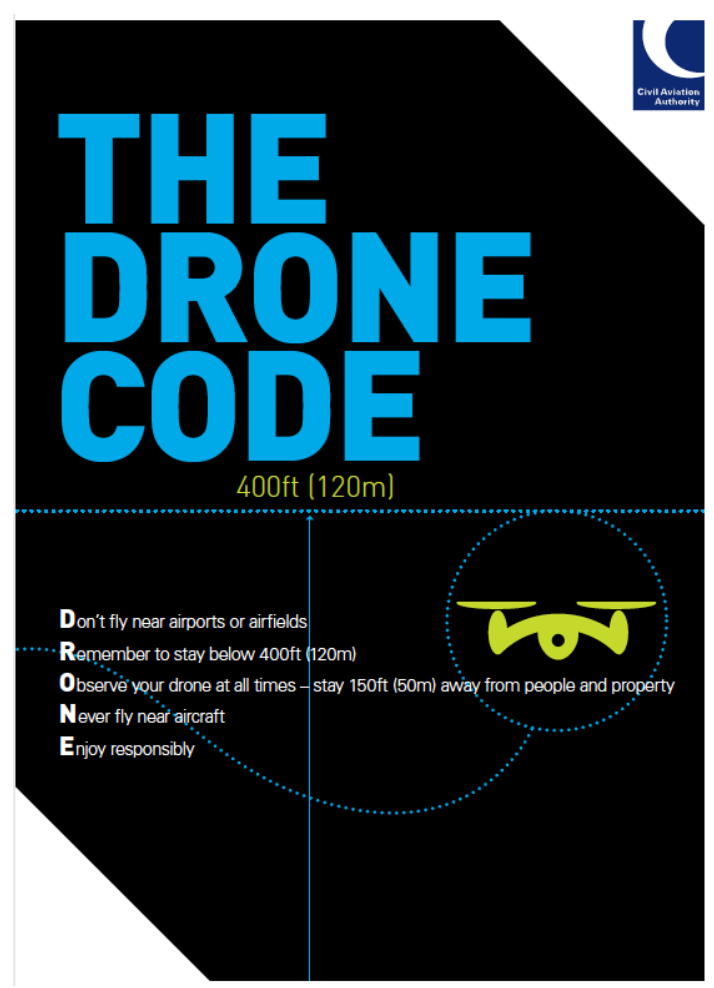

Figure 2: UK: The Drone Code 


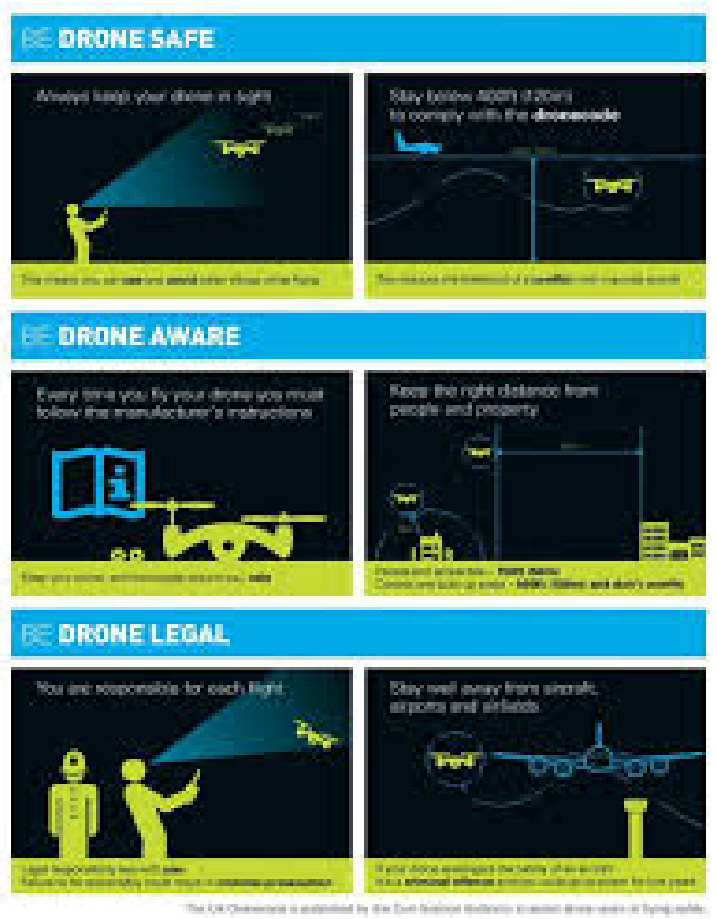

Figure 3: UK: Safe Drone Flying Campaign

For instance in Portugal this topic should integrate the school subject " Cidadania e Desenvolvimento ${ }^{19}$ defined according to the present national educational strategy for the subject as the privileged curricular space for the development of learning processes that have a tridimensional impact on the civic attitude, interpersonal relationship and social and cultural dimensions.

\section{Conclusions}

Safe recreational drone flying comprehends a series of measures, some of which are already in the mind of legislators:

1.Compliance of the product with well defined standards and creditation with the mark CE

\footnotetext{
${ }^{19}$ Citizenship and Development
} 
2.Creditation by recognized institution when the drone is home-built.

3.Registration on the act of purchase and emission of correspondent ID/document/chip ( as it happens with other vehicles as cars) or at administrative office when drones are manufactured

4.Compulsory training of the end-user at school or at credited institution with the emission of certificate

5.Insurance procedure as it happens with other vehicles

However, the harmonious integration of drone technology, and robotic technology in general, into the social fabric necessarily involves more than the definition of legislation, regulations, standards... to which all stakeholders will have to comply. It is essential for the beneficial incorporation of all robotic technology that a raising awareness process grounded on sound ethical principles and involving all stakeholders takes place. This awareness of its benefits and the consciousness of the damages its incorrect use may cause are essential. By the enormous influence of children and youngsters in the household and also because they are not the citizens of the near future, but already citizens of the present, these campaigns should primarily address them.

\section{References}

Air Navigation (Amendment) Order 2018 - Guidance for small unmanned aircraft users, July 2018

European Drones Outlook Study- Unlocking the value for Europe. SESAR European Drones Outlook Study. November 2016

Cfhttps://www.gearbest.com/promotion-RC\%20Clearance\%20Sale-

209.html?vip=4270344\&gclid=CjwKCAjwh9_bBRA_EiwApObaOByF9s0Zyeq7usc8O pnzFDqZHKduzpZ6CxpN3zt-fJk-PcthiO_YDBoCGAMQAvD_BwE

Civilian drones Briefing Paper Number CBP 7734, 11 February 2019

Library of the House of Commons

file:///C:/Documents\%20and\%20Settings/user/Ambiente\%20de\%20trabalho/CBP-

7734.pdf (acessed June 2019)

https://www.cbc.ca/news/canada/drone-airline-airport-incidents-data-canada-1.4973888

Molina, B.M and Oña M. S (2018) The Drone Sector in Europe, in M. de Miguel Molina and V. Santamarina Campos (eds.), Ethics and Civil Drones, 
SpringerBriefs in Law, https://doi.org/10.1007/978-3-319-71087-7_2

RPAS Steering Group, Roadmap for the integration of civil Remotely-Piloted Aircraft Systems into the European Aviation System, June 2013

http://ec.europa.eu/enterprise/sectors/aerospace/uas/index_en.htm

EASA, 'Prototype' Commission Regulation on Unmanned Aircraft Operations, 22 August 2016; For further detail, see the relevant explanatory note

https://www.consilium.europa.eu/en/press/press-releases/2017/12/22/updated-aviationsafety-rules-and-new-rules-on-drones-approved-by-the-council/

https://www.easa.europa.eu/newsroom-and-events/press-releases/easa-publishes-firstopinion-safe-drone-operations-europe

https://eur-lex.europa.eu/eli/reg_impl/2019/947/oj

https://www.easa.europa.eu/easa-and-you/civil-drones-rpas \#0

The House of Commons Library, Briefing Paper

Number CBP 7734, 11 February 2019

www.parliament.uk/commons-library | intranet.parliament.uk/commons-library |

papers@parliament.uk|@commonslibrary 